London, UK

jacquiyoung1@gmail.com

Cite this as: BMJ 2021;375:n2249

http://dx.doi.org/10.1136/bmj.n2249

Published: 20 October 2021
COP26

\section{Creating more sustainable practice: the NHS clinical teams innovating for a greener future}

Local clinical teams are coming up with imaginative ways to reduce carbon emissions that could be easily extended to other hospitals. Jacqui Wise talks to some inspiring people who are helping the NHS achieve its goal of achieving net zero emissions by 2040

\section{Jacqui Wise freelance journalist}

\section{A green ambulance service}

Yorkshire Ambulance Service NHS Trust was the first ambulance service in the world to introduce hydrogen hybrid vehicles as part of its support services. Ambulance services nationally are going a step further and will launch a prototype hydrogen-electric fully equipped ambulance at the 26th UN climate change conference (COP26) in Glasgow. Such vehicles have zero tailpipe emissions and can be fully emission-free if they use electricity from carbon-free sources and hydrogen created using carbon-free electricity.

Replacing diesel ambulances with zero emission models is challenging, explains Alexis Percival, environmental and sustainability manager at the Yorkshire trust. "Pure electric vehicles are unlikely to work in more rural situations as an ambulance needs to be able to accelerate quickly, be capable of going long distances, and can't be off the road for four hours while recharging."

Working with London Ambulance Service and other partners, the trust has sought funding for the Zerro (zero emission rapid response operational) ambulance, which has a range of more than 300 miles and can be refuelled with hydrogen in about 5-10 minutes. The ambulance will be trialled in the community to make sure the technology works. One logistical challenge is that of infrastructure: there are only 13 hydrogen refuelling stations in the United Kingdom, and there aren't enough rapid electric vehicle charging points.

The service already has several other projects under way to reduce its carbon footprint, including installing solar panels on the roofs of 109 ambulances to power electrical equipment and keep vehicle batteries from going flat while waiting for the next call. The trust is also planning an ambulance hub that will be close to net zero. Situated in Hull, it will have solar panels and battery storage and will use greener building materials.

Another of Percival's bugbears is the massive amount of waste caused by disposable face masks. In the first three months of the pandemic, the trust used three million masks compared with about 20 ooo the previous year. Paramedics have to change mask for each patient they see and could use 25 a day each, she says. She has been working for a year with 63 organisations seeking approval for a reusable medical grade face mask that fits better and can be washed up to 50 times.

"The amount of personal protective equipment we are required to use in healthcare systems has to change," says Percival. She says work on sustainability in the NHS has been slow and challenging, but the past two years have seen rapid movement. "Historically, sustainability has been thought of as something that was the responsibility of NHS estates and fleet departments, but suddenly individuals in the NHS are feeling empowered to do something and produce sustainable change on the ground.”

\section{Making pledges to cut carbon}

Sussex Community NHS Trust's Care Without Carbon programme launched five years ago, building on previous carbon reduction efforts, with the aim of establishing more sustainable healthcare. The trust met its initial target of a 34\% reduction in carbon footprint by 2020 and has set new targets for a $57 \%$ reduction by 2025 and net zero by 2040 . Reducing carbon has also produced cost savings-almost £1om (€11.7m; $\$ 13.7 \mathrm{~m})$ over 10 years.

"We took a holistic approach and looked at sustainability through the whole operation of delivering healthcare," says communications manager Hayley Carmichael. "We considered everything, from the journeys we were making to what we bought and how we disposed of it." says. And this applies to the people who work in healthcare. To this end the programme tackles staff wellbeing through the lens of sustainability; for example, by supporting staff to walk or cycle to work. This includes help to purchase bikes, free bike surgeries, shower facilities, and bike storage. To further support staff to leave their cars at home, electric and hybrid pool cars are available for staff to travel between sites or to visit patients. One community nursing team uses an electric bike.

The Care Without Carbon programme has been taken on by several trusts in the region including Sussex Partnership NHS Foundation Trust, East Sussex Healthcare NHS Trust, and Sussex and Surrey Healthcare Trust. Dare to Care is an engagement programme developed to support the carbon reduction programme. It invites healthcare staff to
"The most sustainable healthcare is self-care," she 
pledge to do something to reduce their impact on the environment or boost their wellbeing. The menu of dares includes, "take a walk," "meat-free Monday," "one less car journey," and "switch it off," which encourages people to switch off lights in empty rooms and turn off electrical items. The "make it personal" pledge asks staff to reduce the number of emails they send and instead have a face-to-face conversation or telephone call. As well as the environmental benefits of storing fewer emails on servers, this could make for a more manageable inbox, foster a feeling of a shared workplace, and improve wellbeing. More than 11 ooo dares have been taken so far across three NHS trusts.

\section{Nitrous oxide mitigation}

Nitrous oxide is an anaesthetic agent widely used in several clinical specialties, including midwifery, dentistry, obstetrics, and emergency medicine. It is over 250 times more potent than carbon dioxide as a greenhouse gas and is a dominant ozone depleting substance that can persist in the atmosphere for 120 years. NHS nitrous oxide emissions are comparable to 128 ooo flights from London to Australia a year.

Alifia Chakera, lead pharmacist for theatres and anaesthetics, started researching ways to mitigate the use of anaesthetic gases when she joined NHS Lothian. The board reduced the use of the extremely environmentally damaging desflurane but could not seem to make any progress in reducing nitrous oxide use, which constitutes around $80 \%$ of the total anaesthetic equivalent "carbon footprint." When she investigated further, she realised that the use of nitrous oxide in theatres was actually really low: the main problem was system waste.

Waste occurs in several ways, Chakera says. A small leak, or several microleaks, can soon add up. Leakage can occur at the manifold connections of gas cylinders, at outlets, or anywhere in the pipe network. Another problem is flawed system design and poor stock management. Theft can also be a problem because nitrous oxide is an established recreational drug. "The way we deliver nitrous oxide is the problem; we are essentially oversupplying it,” she says.

Chakera's research confirmed that all 16 NHS sites investigated reported high volume loss of piped nitrous oxide-close to $95 \%$ on average. Work to reduce system wastage of nitrous oxide is now embedded into the Greener NHS programme and is being promoted through the UK. "Nitrous oxide is the anaesthetic agent with the biggest carbon footprint, and we cannot afford to fail," says Chakera. "However, there is no reason that we can't achieve zero emissions of this agent within the next five years."

University Hospitals Bristol NHS Foundation Trust has also made advances on this front, encouraging use of the lower carbon alternative sevoflurane in place of desflurane and raising awareness among clinicians and providing information through QR codes on machines.[1Error! Hyperlink reference not valid.]

\section{Ensuring green views are represented}

Green at Barts is a group of over 100 staff members-including nurses, doctors, physiotherapists, librarians, and managers-aims to support Barts Health NHS Trust to achieve its reduction in carbon emissions and sustainability goals. It is a powerful example of how people working together can educate, advocate, and change ways of working in an NHS trust.

"My message would be that anybody can do this," says Florence Wedmore, who was a junior doctor when she started the group two years ago. "Once you start having conversations with others and join together you have a greater impact.”
The group is encouraging the trust to declare a climate and health emergency following the example of Great Ormond Street Hospital for Children and others. Working with trust sustainability leads, they have ensured that green views are heard at every stage of the Whipps Cross site rebuild, with the ambitious target of it becoming the world's first net zero hospital.

A priority for the trust is to ensure that sustainability is integrated into all quality improvement programmes. "If we are changing our services, we need to look at not only the clinical outcomes but whether we are doing something that is positive for the environment, and are we measuring that?" says Wedmore. The Sustainability in Quality Improvement framework measures the health outcomes of a service against its environmental, social, and economic costs and impact.

The group holds a regular green forum at which senior managers hear ideas from people working directly with patients. The people employed to think about sustainability are in the trust's estates team, but Nadia Audhali, a paediatrician and joint vice chair of the group, says that it's important that clinicians get involved too. "At our trust, there are 17000 staff employed, and because we are on the ground and have lots of interactions with staff and patients, we are in the position to amplify messages and priorities," she says.

\section{Greening and wellbeing}

In the first covid-19 lockdown, junior doctor Tom Downs started a vegetable garden on a piece of scrappy land outside his hospital accommodation in Ysbyty Gwynedd, Wales. Without waiting for official permission, he dug it over and planted potatoes, beetroot, carrots, herbs, and sweet peas. People donated gardening magazines, seeds, tools, and topsoil. "It created a sense of community with the other doctors, and one consultant called it the sanity garden," says Downs. The garden provided a welcome respite from the stress of working at the height of the pandemic and had a positive effect on his mental health. "It was so nice to have a bit of time doing something productive outside, getting my hands in the ground, and actually growing something."

Downs is founder of the hospital's green group, which has more than 80 members. A lot of the work has been on engaging staff and connecting to green groups in other hospitals throughout Wales. They have collaborated with Magnificent Meadows and NHS Forest to plan for meadow restoration and to plant trees on site.

The group is also exploring ways to increase vegetarian and vegan meal options in the hospital canteen and to set up contracts with local growers to supply food. The group is trying to increase awareness of waste, and the hospital took part in a reusable mask pilot scheme. The anaesthetic department has also been working on reducing the use of harmful gases.

Downs says that he is seeing growing interest in environmental sustainability and climate change among his colleagues. He hopes the hospital will find some protected time for some staff members to be fellows in sustainable healthcare and for a clinical lead and an executive lead for sustainable healthcare.

Downs feels that this will be important to acknowledge, support, and coordinate the growing energy and ideas that staff have. "I have been inspired by how committed my colleagues have been to sustainability, as a growing number of us became more aware of how the climate emergency impacts health, no one could face delaying action especially when we could see we could make a difference at work. In hospitals during a health emergency, we all work as one team and don't delay treatments that can protect our patients' health." 
Provenance and peer review: Commissioned; not externally peer reviewed.

Competing interests: I have read and understood BMJ policy on declaration of interests and have no relevant interests to declare.

$1 \quad$ NHS England. Putting anaesthetic-generated emissions to bed. https://www.england.nhs.uk/greenernhs/whats-already-happening/putting-anaesthetic-generated-emissions-to-bed/ 